\title{
JOURNAL.RU
}

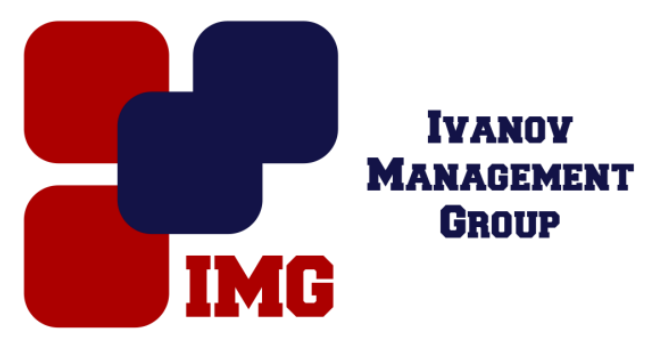

Надежкин М.А.

Нижегородский Государственный Технический Университет им. Р.Е. Алексеева Нижний Новгород, Россия

doi: $10.18411 / 1 \mathrm{j}-31-07-2017-19$

idsp 000001:1j-31-07-2017-19

\section{Тенденции и перспективы развития процесса проектирования отказоустойчивых вычислительных систем}

\section{Аннотация}

Рассматривается вопрос проектирования отказоустойчивых вычислительных систем. Существует два традиционных подхода к обеспечению их отказоустойчивости: использование элементов с высокими показателями надежности и введение избыточности. Для каждого из подходов выдвинуто предположение о тенденциях дальнейшего развития.

Ключевые слова: отказоустойчивость, надежность, микроминиатюризация

Вопросы обеспечения отказоустойчивости вычислительных систем известны достаточно давно [1].Актуальность данной проблемы обусловлена повышением степени информатизации необслуживаемых объектов и объектов, в которых отказ системы может вызвать тяжелые последствия, такие как угроза жизни или здоровью людей, а также большие материальные издержки.

Один из подходов к обеспечению отказоустойчивости ориентирован на высокие показатели надежности, обеспечиваемые использованием элементов и схем с большим запасом надежности и повышенным вниманием к технологическим процессам их изготовления. Очевидно, что повышение показателей надежности за счет развития технологических процессов производства радиоаппаратуры положительно повлияет на данный метод обеспечения отказоустойчивости вычислительных систем. 
Другой подход к обеспечению отказоустойчивости не исключает появление отказов, но их негативное воздействие предотвращается или минимизируется за счет введения избыточности[2]. Сложность данного процесса проявляется в условиях ограничений по массе и габаритам, накладываемых на разрабатываемую вычислительную систему. Можно предположить, что дальнейшее сокращение размеров и массы радиоаппаратуры упростит процесс введения избыточности в разрабатываемые системы.

Из вышесказанного следует, что повышению эффективности обоих способов обеспечения отказоустойчивости будет способствовать развитие микроминиатюризации- направления научно-технической деятельности, основными задачами которого являются уменьшение габаритов, массы и стоимости радиоэлектронной аппаратуры при одновременном повышении ее надёжности и экономичности за счет совершенствования схемотехнических, конструкторских и технологических методов [3].

Перспектива развития процесса проектирования отказоустойчивых вычислительных систем тесно связана с совершенствованием средств микроминиатюризации. Однако, микроминиатюризация оказывает не исчерпывающее влияние, т.к. прогресс в области обеспечения отказоустойчивости вычислительных систем может быть достигнут в том числе за счет совершенствования схемотехнических и алгоритмических решений.

1. Авиженис А., Отказоустойчивость - свойство, обеспечивающее постоянную работоспособность цифровых систем // ТИИЭР. - 1978. - №10 (т.66). - С. 5 - 25.

2. Sil'yanov N.V., Fault-tolerant on-board computers design problems // Modern informatization problems in the technological and telecommunication systems analysis and synthesis: Proceedings of the XXI International Open Science Conference. - Yelm, WA, USA. - Science Book Publishing House, 2016 - P. 283-288.

3. Алексенко А. Г., Бадулин С. С., Барулин Л. Г. и др. Основы проектирования микроэлектронной аппаратуры / под ред. Б. Ф. Высоцкого. — М.: Советское радио, 1978. $-352 \mathrm{c}$. 